\title{
REFUGEES AND HOMELESSNESS: ANALYTICAL FOCUS ON THE SETTLEMENT VILLAGES
}

\section{Hiranthi Pathirana}

The eighteen years of ethnic war in Sri Lanka has created a kind of people whom the international community now calls the 'internally displaced people' or the IDPs. According to the 1995 estimates, there were about 85000 displaced persons (IDP) in Sri Lanka, and by now this number must have increased two fold. This includes people of all racial backgrounds, Sinhalese, Tamils and Muslims. The IDPs have initially started temporary shelter in many part of the country, it is believed to be safer from the war, but during the years of uncertainty they have now been transformed in to permanent places.

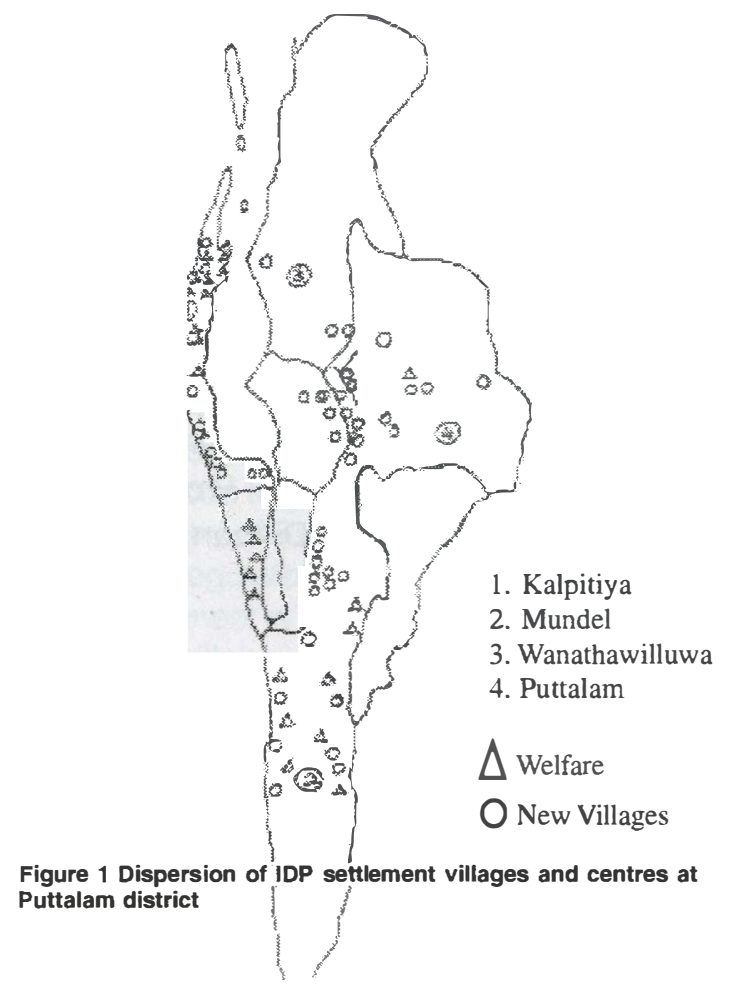

There are two kinds of situations that provide spatial refuge for the displaced persons: the welfare centers and the resettlement villages. The intention of the Welfare centers were to provide immediate relief to the bereaved families, and to offer them the temporary facilities to live, so that they could return to the village from which they were displaced. With out a sign of an end to the war, the waiting has been stretched to years and indeed an understanding that there is perhaps no return. While the welfare Centers descended to the state of 'formalized squatter Settlements' having had little hygiene, lack of infra structure, inadequate space and over crowding, the residents have been able to persuade well wishers, NGOs and other organizations to offer finan- cial assistance and other resources to bail them out of the welfare centers. The result has been the setting up of new settlements adjoining, or in close proximity to the welfare centers, where land was available and therefore could be "purchased" by the IDPs to set up new homes. The financial assistance of many organizations such as the MSPR \&R( Minstry of Planning, Rehabilitation \& Reconstruction ) has been tremendously helpful in the setting up of such settlements.

This research study focuses on the district of Puttalam and analyse the two kinds of situations which has the largest concentration of refugee housing situations in the island. The research was conducted in the year 1999 for the subject of social studies for the degree of M.Sc. in Architecture at the Department of Architecture, University of Moratuwa. The research was based on the analysis of two main housing situations, namely the Welfare Centers and the Resettlement Villages. Almost all the Welfare Centers and Resettlement Villages were visited to get the overall understanding of the situation of refugee housing conditions in the Puttalam district. Particularly four settlements were identified for the research study, out of which two main settlements were considered for this research paper. The research was conducted by site explorations on foot and measured drawings done at the site.

\section{Results of the analysis}

Much of reconstruction of settlements and houses are done largely as "object making" where the essential place making has been ignored. It seems that most of the reconstruction does not provide the kind of "places" they had cherished as the part of their life in the newfound settlements here nor are there opportunities to create them.

\section{Identification of the spatial qualities of a settlement}

The schemata of a settlement, has shown notable differences from that of a naturally evolved settlement . These elements 'house and the 'community space' are the basic sectors of spatial elements in the settlement. Family privacy is minimal due to the fact that there are no breathing spaces created between the hosing plots. This has resulted in a closely built up settlement, which contribute to visual or noise disturbances. In the existing settlements it is identified that as the housing plots are placed long length of rows along the roads, there is no provision for cluster formation of 
houses. There is absolutely no intimacy created within the settlement. As a result it does not allow for cohesion between the groups of the villages. Uniformity, frigidness, lack of variety and congestion has resulted in the settlement pattern now, with the current planning methods employed to plan sites and divisions This has been identified as the ultimate result of "drawing board division" of setsquares and rulers.

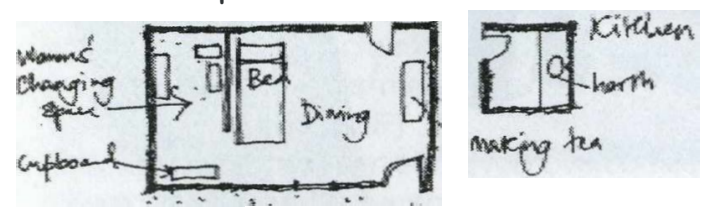

Figure 2 Typical Plan of a house

- Issues of accommodation.

When considering the typical plan of a house, with generally an 110 sq.ft area in plan, accommodating a number of activities seemingly difficult with in the available space.

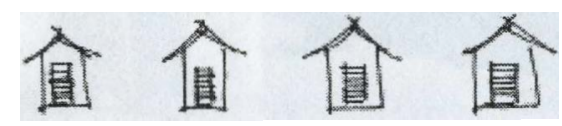

Small hut type houses with thatched roof

Figure 3- Issues of accommodation

- Loss of privacy as a major iss de

It is evident that the typical arrangement does not allow for any personal privacy in the common housing arrangement. $80 \%$ of the houses in Karambe welfare center are in this typical situation.

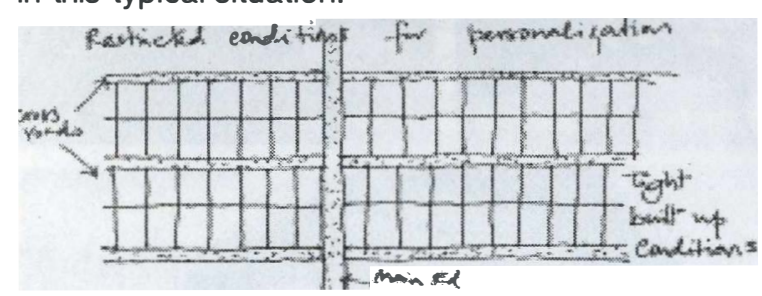

Figure 4 -Grid Pattern of the Housing Layout

\section{- Personalization}

It seems that due to lack of privacy and personal space in the individual house, this qualitative aspect of communication with personalization interms of social, and individual identity cannothave gained in the refugee community.

\section{- Identity}

Variety and individual identity have hardly ar: opportunity to manifest and the grid - iron runs across the land erasing every sense of differentiation that exists.

\section{- Disorientation}

Disasters cause disorientation. unsympathetic reconstruction causes more disorientation and alienation, resulting in a severe sociological, and economic loss. Reconstruction after disaster in the case of IDP is found often geared towards the mere replacement of lost houses and theyare looked at as "giving houses" rather as "objects" without emphasizing the fact of making "home" in them.

\section{Loss of Security}

Security has become a major issue in terms of physical and psychological implications.

Physiological and psychological security with in the community existence The prevailing need of physiological security for spouseless women, children and the aged.

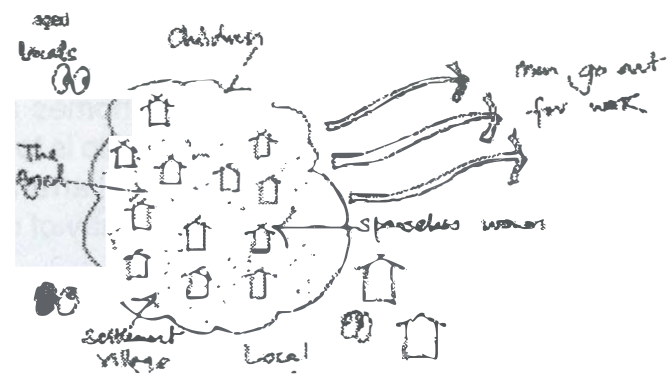

Figure 5-Issue of Security in the Settlement

\section{- Territoriality}

It has been identified that the emphasis on territoriality is greater in the IDP welfare centers and their resettled villages. Christian Norberg Shultz has identified Man's deepest need to have an existential foothold. As where ever he/she lives it is evident that this need for foothold is expressed well in the settlements of the IDP.

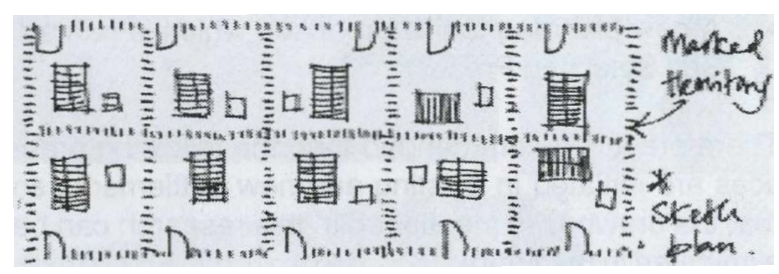

Figure-6 Clear Demareation of Housing Plots

\section{- Sense of belonging}

Sense of belonging will be created with the enwrap of factors such as security and territoriality. The rest become the donations for common use, such spaces have evolved as community spaces, which have eventually sustained a "sense of belonging" in the community.

Ecological degradation has been triggered off due to the mass settlements with out giving consideration to the existing natural habitat and terrain.

\section{- Land clearances and deforestation}

The situation of the dry zone is increased with these circumstances. As a result land will become scarce for vegetation in the future.

\section{- Pollution}

Environmental pollution has increased with the mass movement of people in the area where the land has been denuded of trees.

- Poor sanitary conditions 
- Refuse disposal

- Poor drainage systems

- Sewerage

- Higher energy consumption is segregated to one area in terms of water, electricity and fuel.

- Resource depletion due to too many concentration of people on site. (The over bearence)

\section{Reconstruction after Disaster-}

"Place making" Is an extremely important because if it is a highly sensitive issue related to the homing of the displaced. Therefore it is vital to involve the IDPs themselves in the process of creation of their homes and places. What architects and planners could do is to set this process in motion. Looking at the overall arrangement of the village settlement in its natural way of creation according to their wishes.

- In the research conducted on the basis of assessing the current practices of reconstruction after the war, an attempt was made, with the intent on of proposing social and architectural significant improvements.

- For this purpose of understanding and assessing the social and architectural implications, the ideas of home and place were employed.

- It was discovered that the present practices of resettling do not provide the opportunities for 'making home' and 'places' in the reconstruction process and that this has severe implications for the recovering process.

- A new planning tool is proposed which is named, Self Selecting Process.

Therefore it is recommended that the following practices are initiated in existing and new settlements so that the drawbacks mentioned in this research can be eliminated in the future.

\section{A) Existing settlements}

01 Giving regard to social and cultural aspects of design: without "blind" assumptions on their needs.

02 Injection of open spaces and variety to the already existing settiements villages.

03 Observation of informal settlements ensuring optimal collaboration between formal and informal sectors in design

04 Promotion active user participation in the development process by having various design decisions in the hands of the actual user if on going developments permit..

05 Allow overall control of settlementdesignin a healthy approach to be done by the planners and social scientists who understand the above issues.

06 Identifying the possibility of a new planning method to be introduced to eliminate the existing conditions. (This is out lined below in section)
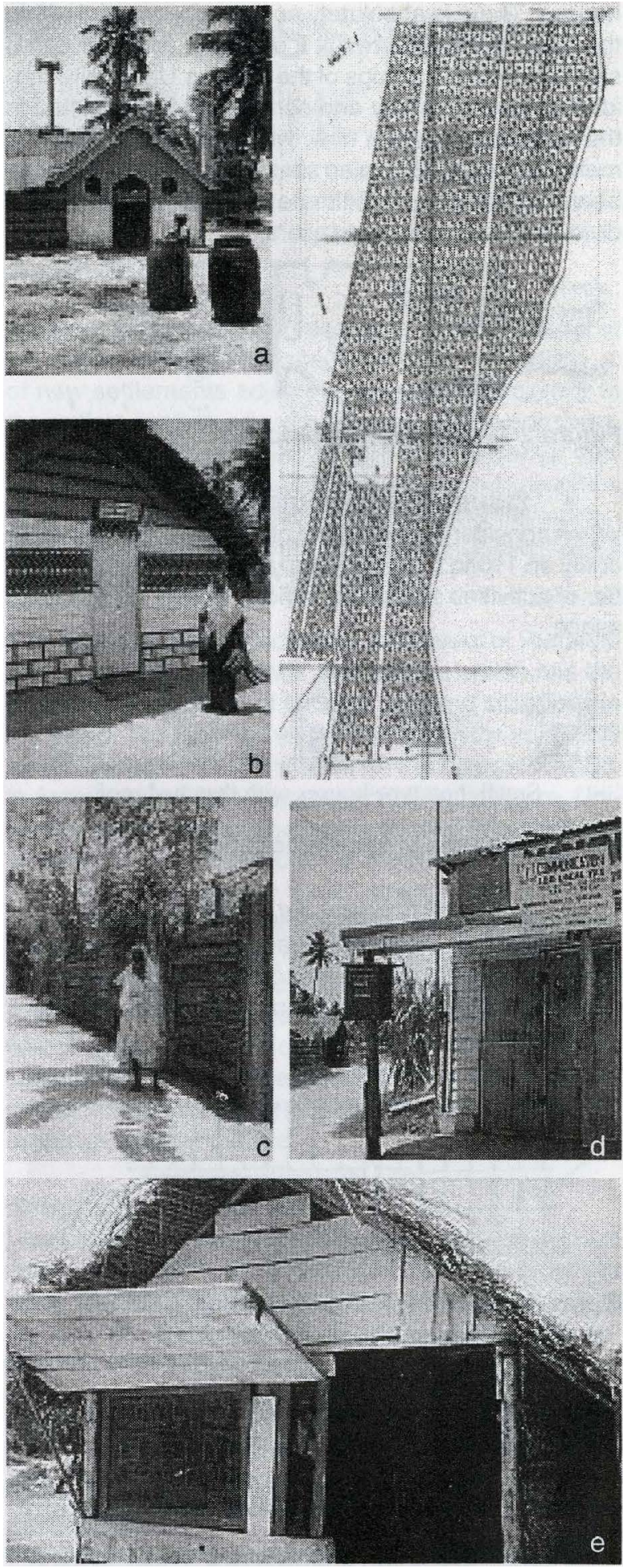

Figure7 -Tipical layout of a Settlement

The Mosque of Karambe (Welfare Center)

b

School of Karambe (WC)

Cadjan Demarcations of Karambe (WC)

d

The Post Office of Karambe (WC)

The Salon of Karambe (WC) 


\section{B) New settlements}

01 Formation of new settlements as a necessity for the IDP with no signs of end to the war instead of camps and welfare centers.

02 It is proposed that the planning method which has been proposed by Vikram Bhattand Jesus' Navarrete (Open House intemational journal vol. 16 No 04 1991) is taken as the basis creating solutions to the problems discussed. This method is called the Self Selecting Process (SSP)

03 This design process can effectively overcome most drawbacks inherent in current planning methods and produce lively and user responsive built environments, which also can be cost effective.

\section{C) Recommended Self Selection Process (SSP) for creating new settlements}

"Some of the best new environments today are to be found among the spontaneous settlements of developing countries: some of the worst are designed by architects"

C.1 The basis to this recommendation and the method is presented below. The method is illustrated by an example in India.

C. 2 This can be explained by the characeristics inherent in the natural settlements in which the users themselves take various decisions by themselves.

C.3 SSP is a planning method that relates the development process of the unplanned settlements also, which overcomes the inadequate facilities of infrastructure. Therefore this planning method is based on t vo principals rooted in the planning process of informal settlements, they are: The autonomous development and continous growth.

\section{"Autonomous growth"}

- The idea behind autonomous growth is that the user should be involved in the housing process at every level of design. For a built environment should have a greater contribution from its future residents for it to be culturally appropriate and socially acceptable. Autonomous growth suggests that to achieve this, user participatiopn is important from the micro level of individual homes to the community and ssettlement design.

- Duties of the regulatory bodies and design team should be decreased from the level of a controller of all the design decisions to the level of a general regulator of the settlement.

\section{Continuous development}

- It is identified that continous development allows chain of events to take place in an unbroken manner contrary to the conventional moder! housing
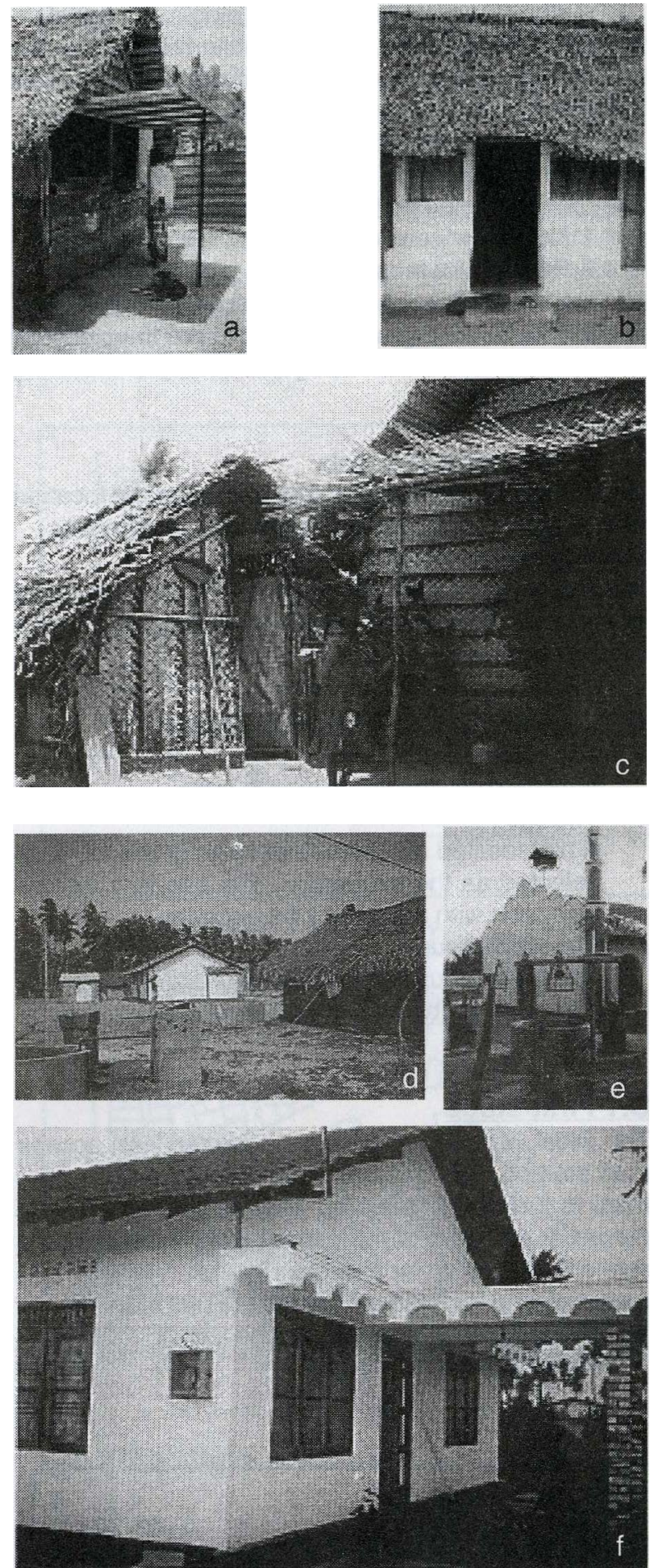

Figure 8 Erikkalampiddy Resettlement Village

a

Beef Stall

b

House with cement rendered floor

c

Atipical cadjan house

d

School Erikkalampiddy

e

The Mosque of Erikkalampiddy

f

A Finished house 
methods, which develops in a single or a few definite stages. In this way the settlement pattern becomes coherent avoiding artificial or mechanical order.

\section{C.4 SSP is based on four planning strategies}

\section{C.4.1 No pre conceived plan}

C.4.2 Progressive infrastructure

- Instead of planning the entire infrastructure at once, it is introduced gradually without pre imposing on the settlement and losing the quality of the living environment.

\section{C.4.3 Self selection of plots}

Under the SSP, families are free to choose the location of their plot according to their particular preferences

\section{C.4.4 Variety of plot sizes}

In the process of SSP there is no pre-determined size or shape of plots based on economic classification of the beneficiaries.

\section{D) The simulation, As an example}

- The place :

A rapidly growing urban area in India

- The site :

A plot located six kilometers north of the city was selected as the simulation. The site is a feature less plain with a total of 2.84 hectares.

- The client group

The client group representative of a low income urban community, the detailed profile of a 500 families.

\section{D.1 First stage}

The initial infra structure was introduced, An access road starting from the main road that links the settlement to the city. A bus stop was placed immediately placed at the west of the access road, considered a convenient location for all residents.

A strip of land for hawkers beside the bus stop. (B)

The architect's / Planners office as (C)

Public taps as no 1 and 2

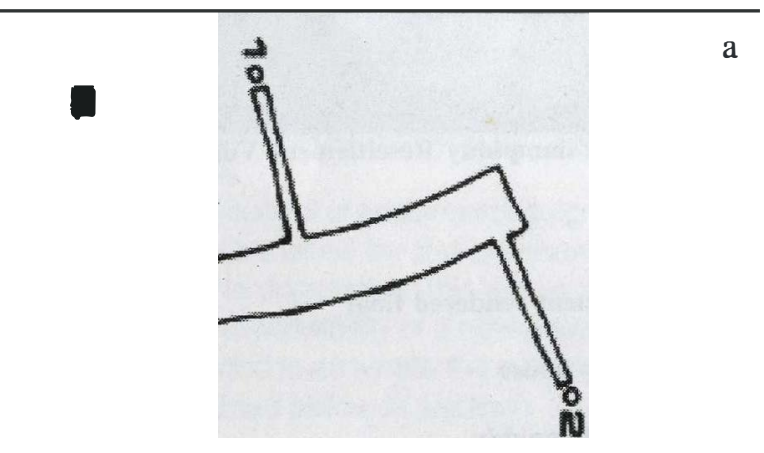

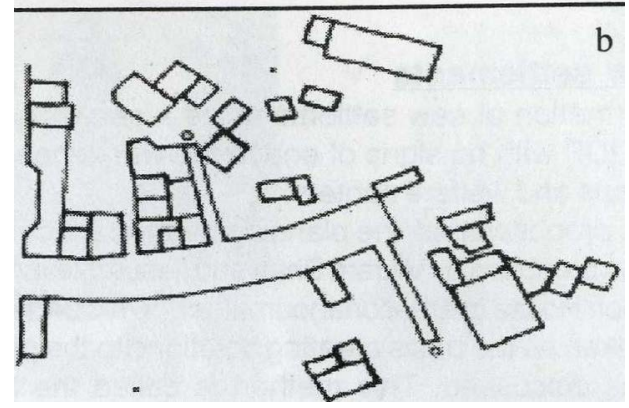

Figure 9 ( a)+( b) First Stage development

\section{Selection of plots}

Plots started to cluster to the west of the access road, around public water tap 1 and 2 and along the access roads to these taps. Some took the advantage of the go0ood business location and began to locate along the access road. Some took the advantage of the two trees that existed there, and also having close links with the public taps around.

\section{D.2 Second stage}

Introduction of a third public water tap with two new paths. Finally a market square ' $D$ ' was created next to the existing access road. The shape of the marketsquare was defined by the spread of the existing trees and surrounding plots.

\section{Self selection of plots}

A considerable amount of clustering around public water taps 1, 2 and 3 took place, around the southern most trees and market square. New plots developed along the access road for commercial reasons. The smaller paths, acting as pedestrian links between stand pipes, and access road or tree squares and access road 0 , also attracted a number of new lots.

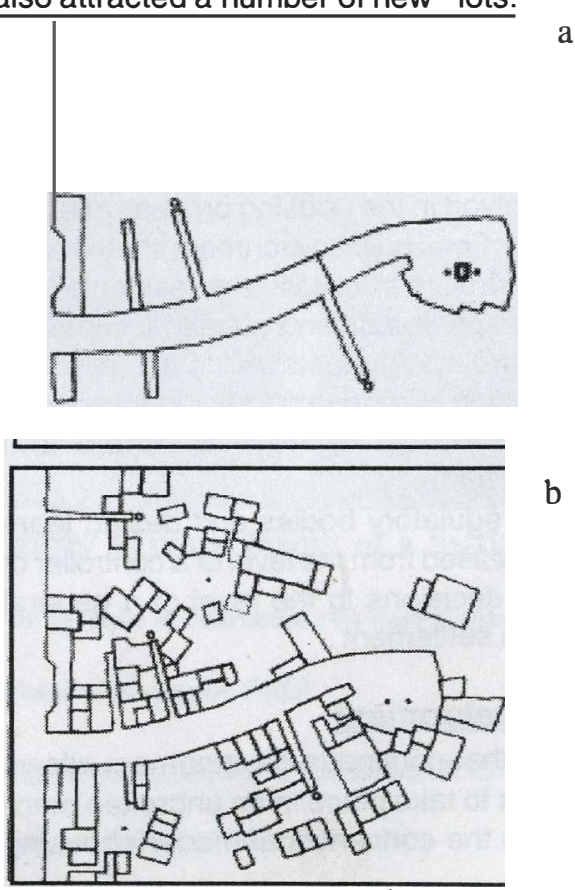

Figure 10 ( a )+( b) $2^{\text {nd }}$ stage development 


\section{D.3 Third stage}

Two more public taps, number 4 and 5 each with a path to the west of the central square was added, its shape based on the location of existing plots. Another path connected public water tap number 1 to he access road and an adjoining square with a tree.

\section{Self selection plots}

The main road and the access road started to consolidate. Plots at street inter sections were occupied first, because of the advantageous business location.

Some family groups had to leapfrog to other locations as the areas surrounding their kinsmen were saturated. There was no clustering around stand pipe number 5 which could be because of its northern most location and relative isolation from other amenities.

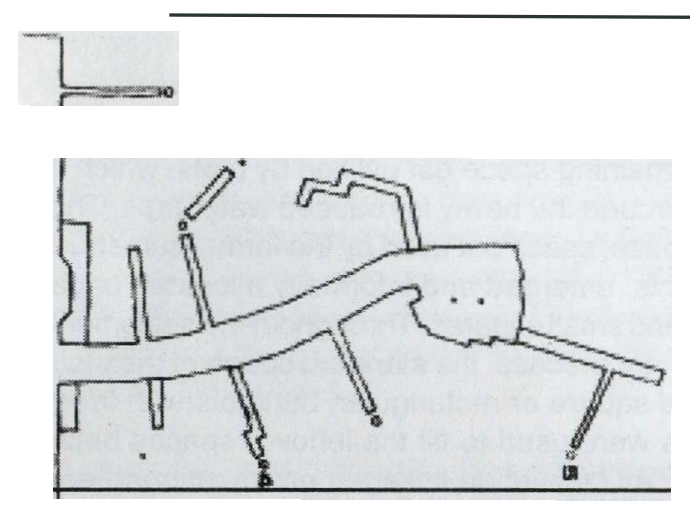

a

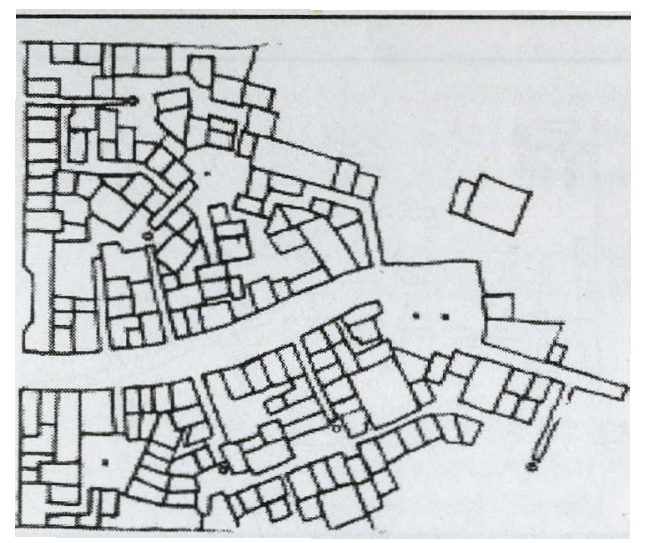

b

Figure11-( a)+(b)Third stage development

\section{D.4 Fourth stage}

Infrastructure

The access road was extended towards the north west corner of the site from the market square. Public water tap no 6 and a path was added to the west of the market square. Another public water tap no 07 was introduced to the west of the new section of the access road. A kindergarten $(E)$ was inserted just off of the access road between public water tap no 06 and 01 . The kindergarten was carefully fitted within the open space left by the surrounding plots. Finally a small square and a path were added to the street leading from the main city road to public water tap number 03 .

\section{Self selection of plots}

It was identified that good clustering occurred around the new extension of the access road and public water tap number 07 . This was largely due to the arrival of a large number of families of the same back ground, a mere coincidence. The southern edge the settlement was already saturated, so the new group had to stake out plots to the north. The area between the two new public water taps number 06 and 07, also began to fill up. The southern quarter of the settlement was now saturated with plots, and the spaces around trees and public water taps had acquired a distinct character.

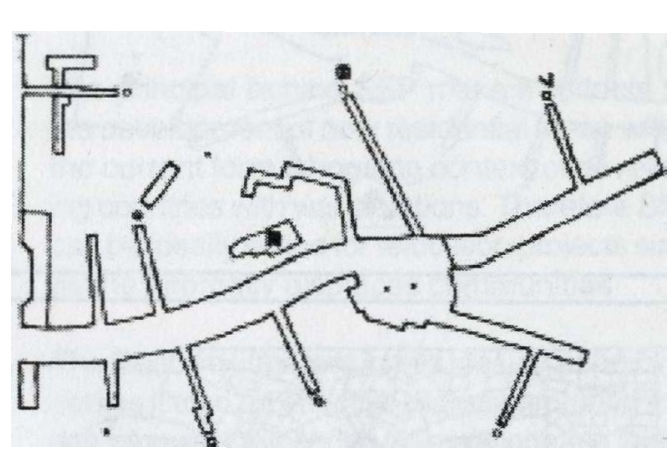

a

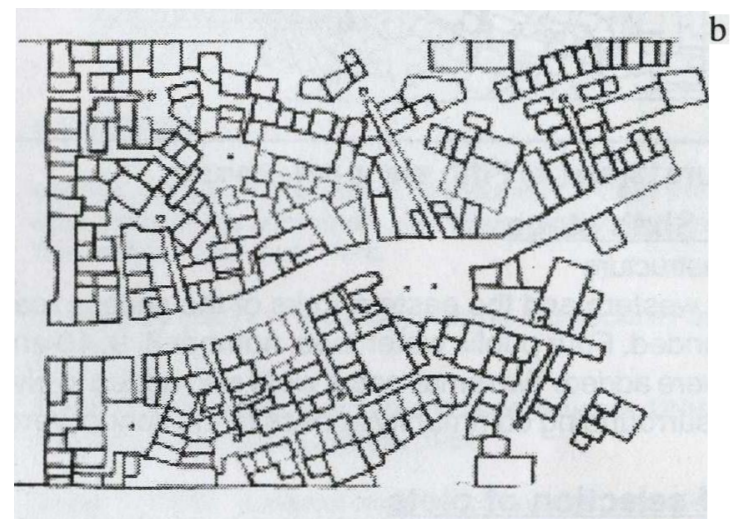

Figure-12( a) +(b)Fourth stage development

\section{D.5 Fifth stage}

Infrastructure

A large school (F)

The school was added to the northern section of the settlement incorporating an existing tree. The school also incorporated a large play area $(G)$. A clinic $(H)$ was added just beyond the market square along the west side of the access road. A new section of road was added to the western fork of the access road, and its eastern flange was also extended. Two large squares, (land $\mathrm{J}$ ) added for religious purposes, were developed around water taps 05 and 06 . Small religious shrines were integrated in these two squares. 


\section{Self selection of plots}

Plot allocation in the southern $2 / 3$ of the settlement was completed and the space between the fork of the acccess road started to fill up. Clustering around public water tap 05 was completed and plots started to expand to the north. The introduction of the religious structures consolidated the spaces surrounding the two squares described in stage four.
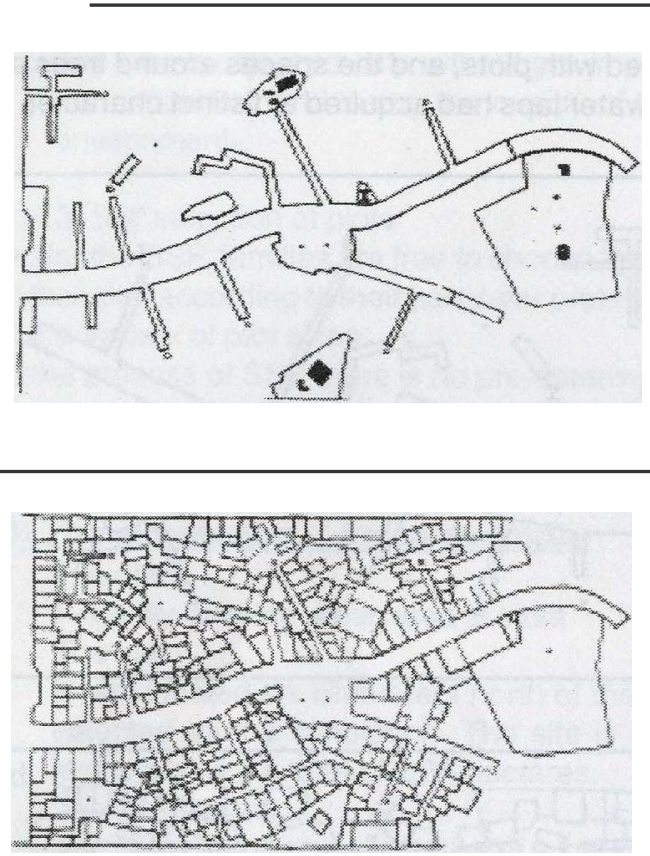

Figure13(a)+(b) Fifth stage development

\section{D.6 Sixth stage}

\section{Infrastructure}

The western and the eastern forks of the access road extended. Four public water taps, number 8, 9, 10 and 11 were added. Two small paths were also added to give the surrounding community access to the school yard.

\section{Self selection of plots}

The entire western side of the settlement was now saturated with good clustering around the new stand pipes. The area between the two forks of the access road to the south of the school got filled. Only about $1 / 8$ of the settlement in the north - east corner remained vacant. This vacant area had only one isolated plot resulting from leapfrogging.

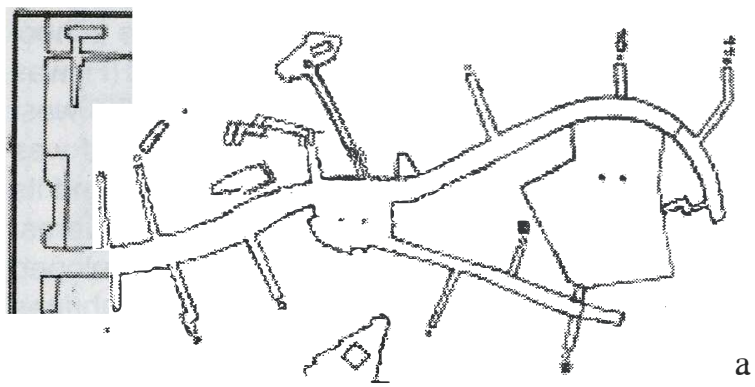

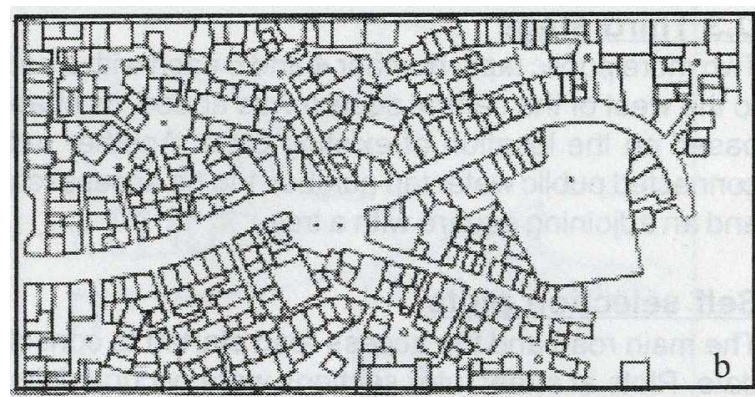

Figure14(a)+(b) sixth stage development

\section{D.7 Seventh stage}

\section{Infrastructure}

The last stage of the infrastructure implementation consisted of the addition of two public water taps, number 12 and 13, one at the western fork and another at the eastern fork of the access road.

\section{Self selection of plots}

The remaining space got utilized by plots, which clustered around the newly introduced water taps. The left over space, space not used by the formal infrastructure and plots, emerged and informally allocated unpaved paths and small squares. Throughout the settlement development process, the standard shape of the plots remained square or rectangular, but plots with irregular shapes were used to fill the leftover spaces between others. All circulation linkages not mentioned earlier, were formalizes during this stage.
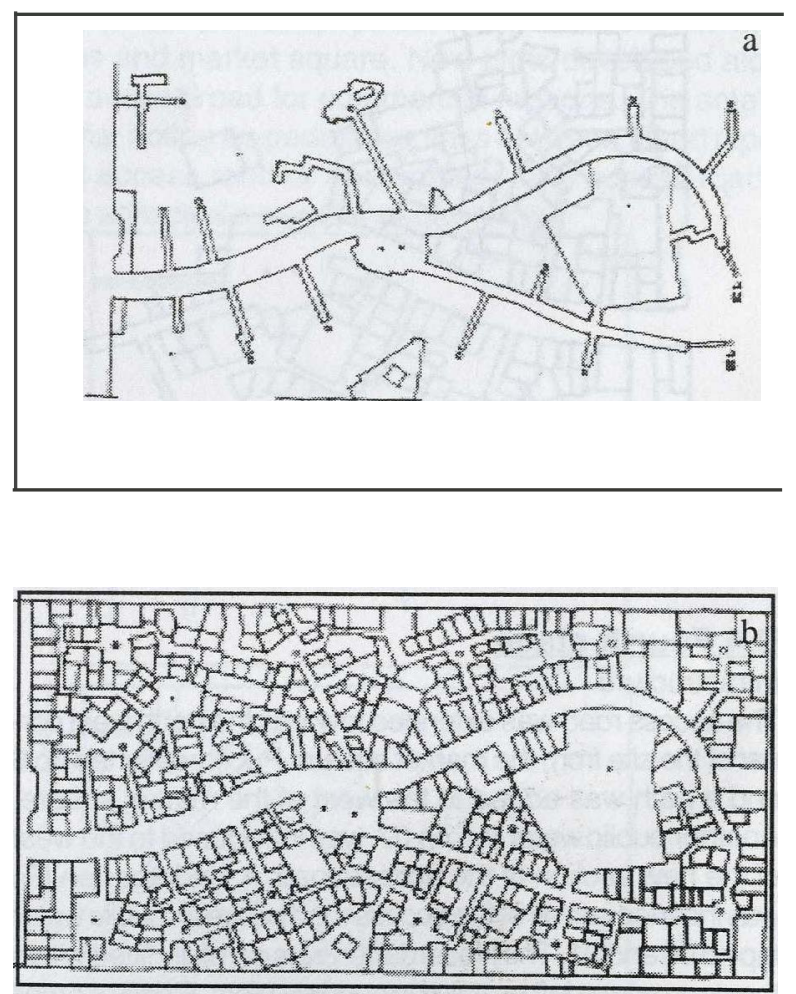

Figure15(a)+(b) seventh stage development 


\section{E) Project appraisal}

- The physical characteristics of the simulation project explained in the earlier sectionsuggest that the selfselection process (SSP) has in deed overcome most drawbacks inherent in the conventionally planned projects.

- It can be identified that in comparison with the conventional housing designs, the stimulation was able to respond to the needs and backgrounds of individual families and the community.

- As an overall result this creates more green spaces, breaking tight and congested situations of close built ups

- The process offered a unique response in meeting the user's needs, since it allowed, families to choose the location of their plots and neighbors and to settle down according their particular preferences. SSP produced an environment responsive to user's needs with varied plot areas, open spaces and road net work well integrated with housing. Mcre significantly, the simulationalso produced settlement with a remarkable sense of community and belonging and socio - culturally cohesive spatial accommodation for its residents.

- As observed, simulation did not make any particular assumption about family income and plot sizes. which is relevant, speciallyy in the case of IDP settlements. Plot sizes and shapes were defined based on several factors and not only on the family income level. As a result this produced a settlement with a wide variety of plot sizes and shapes.

- The simulation also provided both single and multi family plots, and allows to make close kintted relationship with neighbourhood.

- SSP principals also led to the creation of a wide variety of open spaces which are rich, varied and evenly spread through the site which is not regarded in the current processes.

- Different to a conventional design prncess this requires a less planning time on the development of an efficient and culturally appropriate layout whch is important at the face of a disaster.

- The SSP offer general control over the creation of their own living environments. Through an ample control over the location, size and shape of their plots, and the configuration of surroundings, public spaces and circulation, SSP encourage the users to develop a built environment that matches their most particular needs, and supports a stronger community integration. More importantly through an incremental upgrading of houses, infrastructure, and public amenities, SSP offers the users the development of such a built environment according to their economic means.

- For the formal sector, SSP offers a lower initial investment on infrastructure, and a minimum involvement in design, development, and maintenance new residential projects. With such low initial investment in both time and financial resources, SSP offers the formal sector the possibility of developing a greater number of new residential projects.

- $\quad$ The principal behind SSP make it suitable for the development of now residential areas within the current formal housing context of developing countries with war situations. Therefore SSP can be ideally suited for relocation projects such as the internally displaces communities

- The flexibility inherent in this design approach, makes it also an effective planning method that can be easily applied to different context, since its basic rules may be modified to suit different cultural and regional needs. This design approach could also be effectively in various geographical locations.

\section{REFERENCES}

Barakat, S (1993) - Rebuilding \& Resettlement, 9 years later; a case study of the contractor built reconstruction in Yemen, University of New York, York.

Canada, DV (1977) - Psychology of place, Architectural Press, London.

Collins P - A mandate to protect and assist refugees, UNHCR Educations Rencontre Layanne, 1964.

Davis, I (1986) -Lessons from Reconstruction after disasters, international conference on reconstruction of the war damaged areas, University of Teheran, Iran.

Hamidi Nabeel (1991) - Housing Without House, Von Nostrand Rein hold, New York.

Oliver P (1981) - Disaster \& small dwelling, Pergomon Press, Oxford.

Ralph, E (1976) - Place and Placelessness, Pion limited, London.

Rappoport, A - House Form and Culture Prantice Hall inc. New Jercy

Rappoport, A., (1987), " on the cultural responsiviness of Architecture", Journal of Architectural Education, 4(1): 10-15

Tuan, Y (1977)-Space \& Place Edward Arnolde, London .

Ward C (1985) - When we build again, Pluto Press limited, London.

Wikram Bhatt and Jesus Navarrete, Vol.16 No.4, 1991, Open House International. 